\title{
Outcome of Biventricular Repair in Infants With Multiple Left Heart Obstructive Lesions
}

\author{
Anna Cavigelli-Brunner • Urs Bauersfeld • \\ René Prêtre · Oliver Kretschmar • Angela Oxenius • \\ Emanuela R. Valsangiacomo Buechel
}

Received: 15 May 2011 / Accepted: 3 November 2011/Published online: 11 December 2011

(C) Springer Science+Business Media, LLC 2011

\begin{abstract}
The decision to perform biventricular repair for infants with multiple obstructive or hypoplastic left heart lesions (LHL) and borderline left ventricle (LV) may be controversial. This study sought to assess the mortality and morbidity of patients with LHL after biventricular repair and to determine the growth of the left-sided cardiac structures. Retrospective analysis of 39 consecutive infants with LHL who underwent biventricular repair was performed. The median age at surgery was 7 days (range 1-225 days), and the median follow-up period was 34 months (range 1-177 months). Between diagnosis and the end of the follow-up period, the size of the aortic annulus ( $z$-score $-4.1 \pm 2.8$ vs. $-0.1 \pm 2.7$ ) and the $\mathrm{LV}$ (LV end-diastolic diameter $z$-score $-1.7 \pm 2.8$ vs. $0.21 \pm$ 1.7) normalized. During the follow-up period, 23 patients required 39 reinterventions (62\%) consisting of redo surgery for 21 patients $(57 \%)$ and catheter-guided reinterventions for 8 patients (22\%). At the end of the follow-up period, 25 of 34 patients were doing subjectively well; 10 children (29\%) received cardiac medication; 12 (35\%) presented with failure to thrive (weight $\leq$ P3) and $5(15 \%)$ with pulmonary hypertension. The overall mortality
\end{abstract}

A. Cavigelli-Brunner · U. Bauersfeld · O. Kretschmar .

A. Oxenius · E. R. Valsangiacomo Buechel ( $\square)$

Division of Pediatric Cardiology, University Children's

Hospital, Steinwiesstrasse 75, CH 8032 Zurich, Switzerland

e-mail: emanuela.valsangiacomo@kispi.uzh.ch

A. Cavigelli-Brunner · U. Bauersfeld · R. Prêtre ·

O. Kretschmar - A. Oxenius · E. R. Valsangiacomo Buechel

Children's Research Centre, University Children's Hospital,

Steinwiesstrasse 75, CH 8032 Zurich, Switzerland

R. Prêtre

Division of Cardiac Surgery, University Children's Hospital,

Steinwiesstrasse 75, CH 8032 Zurich, Switzerland rate was $13 \%$. Biventricular repair for patients with multiple LHL results in sufficient growth of the left-sided cardiac structures. Nevertheless, residual or newly developing obstructive lesions and pulmonary hypertension are frequent, causing significant morbidity that requires reintervention.

Keywords Biventricular repair - Borderline left ventricle $\cdot$ Left heart lesions $\cdot$ Pulmonary hypertension

\section{Introduction}

Patients born with multiple hypoplastic or obstructive left heart lesions (LHL) present a wide spectrum of cardiac malformations and varying degrees of underdeveloped structures of the left heart, the mitral valve, and the aorta. At one end of the spectrum are mild lesions that are not progressing and may never need an intervention. At the other end of the spectrum is the hypoplastic left heart syndrome with incapability of the left ventricle (LV) to support the systemic circulation. These most severe forms usually are palliated into a single-ventricle physiology, or cardiac transplantation is offered [11].

Single-ventricle palliation consists of a staged surgical approach with several operations, long hospital stays, and a potentially less favorable univentricular physiology at long-term follow-up evaluation, with the right ventricle (RV) in systemic position. Therefore, biventricular repair is favored whenever possible. However, determining whether the left-sided structures are of adequate size and whether their function can sustain biventricular physiology is challenging.

Several predictors of outcome and different management strategies for infants with LHL in view of biventricular 
palliation have been analyzed and proposed. The dimensions of the inflow, outflow, and cavity of the LV have been identified as determinants of early survival among neonates with LHL and aortic stenosis $[11,17]$. Other authors have proposed additional criteria for consideration before biventricular repair in infants with coarctation of the aorta and LHL [1, 24] or multiple LHL [3, 19]. However, more recent reports suggest that these criteria may not be used as strictly as originally recommended $[13,15]$. Thus, definition of clear criteria predicting successful biventricular repair for LHL still is not completely achieved, and the growth potential of the left-sided cardiac structures in these patients is even more difficult to predict. Biventricular repair, even if successfully performed, may imply some burdens such as progression or occurrence of additional obstructive lesions, need for repeated interventions, and persistent pulmonary hypertension.

We sought to evaluate the mortality and morbidity of patients with LHL undergoing biventricular repair and to determine the growth potential of the left-sided cardiac structures.

\section{Methods}

Patients

All patients with multiple LHL born between January 1990 and December 2006 were identified in the electronic database of the Division of Pediatric Cardiology at our institution, and medical records were retrospectively reviewed.

\section{Inclusion Criteria}

Patients younger than 3 months with situs solitus and levocardia, a patent aortic valve (AO), a mitral valve with anterograde flow, and no previous surgical or catheter intervention were included in the study. Diagnosis comprised at least two of the following lesions identified at the first echocardiography $[2,10,21]$ :

- Mitral valve: stenosis (mean gradient $>3 \mathrm{mmHg}$ ), annulus hypoplasia or parachute mitral valve

- Left ventricular outflow tract (LVOT): subaortic stenosis (localized subvalvular ridge or long segmental narrowing with increased Doppler flow velocities) or LVOT diameter less than normal aortic annulus size (indexed to body size)

- AO: stenosis (maximum instantaneous Doppler gradient $\geq 20 \mathrm{mmHg}$ ) or annulus hypoplasia

- Aortic arch: hypoplasia, coarctation or interrupted aortic arch
- LV: LV/RV long axis ratio less than 0.8 or small LV end-diastolic diameter (LVEDD).

Ventricular, vascular, or annular hypoplasia was defined as an indexed dimension with a $z$-score lower than $-2.0[5,8]$.

The decision to perform biventricular repair was based on echocardiographic findings and interdisciplinary agreement between the cardiologist and the cardiac surgeon involved.

\section{Exclusion Criteria}

Patients with nonconcordant atrioventricular or ventriculoarterial connections, total anomalous pulmonary venous connection, or common atrioventricular canal defect were excluded from the study. Patients who died before cardiac treatment or died of noncardiac complications also were excluded.

\section{Follow-up Evaluation}

The following grading system proposed by Ross et al. [18] for pediatric heart failure was used to assess late functional status:

- Class 1: no limitations or symptoms

- Class 2: mild tachypnea or diaphoresis with feedings (infants) or dyspnea at exertion (older children)

- Class 3: marked tachypnea or diaphoresis with feedings or exertion or prolonged feeding time with growth failure

- Class 4: symptoms at rest with tachypnea, retractions, grunting, or diaphoresis.

\section{Echocardiography}

Echocardiograms at admission and during follow-up assessment were retrospectively reviewed. Echocardiography was performed according to the current pediatric echocardiographic recommendations [10, 21]. Left ventricular mass was calculated using the cube formula:

(epicardial volume - endocardial volume) $\times 10.4 \mathrm{~g} / \mathrm{ml}$

[21]. All measurements were indexed to body surface area and standardized to $z$-score by the following equation:

$z=$ logarithm (observed dimension)

- logarithm (mean normal dimension/

standard deviation of the mean normal dimension)

$[5,8]$. Ventricular septal defects (VSD) were classified as absent, small (largest VSD dimension $<50 \%$ of the aortic 
annulus diameter) or large (VSD dimension $>50 \%$ of the aortic annulus diameter).

\section{Statistical Analysis}

Data are presented as frequencies, mean \pm standard deviation (SD), or median and range as appropriate. Measurements from initial and final echocardiographies were compared using the paired Student's $t$-test. Continuous data of two different subgroups were compared using the unpaired Student's $t$-test. Categorical data of two subgroups were analyzed using contingency tables and Fisher's exact test. A $P$ value less than 0.05 defined statistical significance. Actuarial survival and freedom of reinterventions were calculated according to the method of Kaplan and Meier. The local ethical committee approved the study.

\section{Results}

Patients

Biventricular repair was performed for 39 patients (20 females) with LHL. The median age at diagnosis was 3 days (range 1-30 days), with 27 patients (69\%) presenting during the first week of life. The mean weight was $3.1 \pm 0.6 \mathrm{~kg}$, with 27 patients $(69 \%)$ weighing less than $3.5 \mathrm{~kg}$. Six children were born prematurely, with four of them born before 37 weeks of gestation (WG), one born before $33 \mathrm{WG}$, and one born before $30 \mathrm{WG}$. Six children presented with genetic anomalies including five children with microdeletion 22q11 and one child with cystic fibrosis.

All LHL and additional defects are listed in Table 1. The LV measurements at the first echocardiography are summarized in Table 2. A hypoplastic aortic annulus (z-score less than -2 ) was present in 31 children (79\%), and an LVEDD with a $z$-score less than -2 was present in 17 children (44\%). A reduced LV function (ejection fraction $<50 \%$ ) was observed in 11 patients $(28 \%)$. For 32 patients $(82 \%)$, prostaglandin was administered initially to maintain ductal patency.

\section{Initial Interventions}

Initial treatment, performed at a mean age of $14 \pm 23$ days, consisted of cardiac surgery for 29 patients (74\%) and primary catheter-guided intervention for 10 patients. Cardiac catheterization included 10 valvuloplasties of the AO, one of which was combined with aortic arch dilation. One catheterization was performed for advanced diagnostic purposes only. The median age at
Table 1 Diagnosis

\begin{tabular}{lll}
\hline Diagnosis & LHL & Additional lesions \\
\hline Aortic coarctation & 25 & \\
Bicuspide aortic valve & 23 & \\
Mitral valve stenosis & 19 & \\
Aortic arch hypoplasia & 16 & \\
Aortic valve stenosis & 14 & \\
Subaortic stenosis & 10 & \\
Interrupted aortic arch & & \\
- Type A & 1 & \\
- Type B & 7 & \\
Parachute mitral valve & 8 & \\
Mitral valve insufficiency & 3 & 30 \\
Monocuspid aortic valve & 2 & 21 \\
Patent ductus arteriosus & & 13 \\
Ventricular septal defect & & \\
Large & & \\
Small & & \\
Atrial septal defect & & \\
\hline
\end{tabular}

$L H L$ left heart lesion

Table 2 Echocardiographic measurements

\begin{tabular}{lcc}
\hline LV parameters & At diagnosis & At end of follow-up \\
\hline Ao annulus $(\mathrm{mm})$ & $5.6 \pm 1.1$ & $12.3 \pm 3.9^{\mathrm{a}}$ \\
Ao annulus z-score & $-4.1 \pm 2.8$ & $-0.1 \pm 2.7^{\mathrm{a}}$ \\
LVEDD $(\mathrm{mm})$ & $15.9 \pm 4.0$ & $29.5 \pm 7.4^{\mathrm{a}}$ \\
LVEDD $z$-score & $-1.7 \pm 2.8$ & $0.21 \pm 1.7^{\mathrm{a}}$ \\
LV mass $(\mathrm{g})$ & $10.3 \pm 7.7$ & $44.9 \pm 28.0^{\mathrm{a}}$ \\
LV mass/BSA $\left(\mathrm{g} / \mathrm{m}^{2}\right)$ & $48.2 \pm 31.7$ & $75.9 \pm 33.5^{\mathrm{a}}$ \\
\hline
\end{tabular}

$L V$ left ventricle; $A o$ aortic; $L V E D D$ left ventricular end-diastolic diameter; $B S A$ body surface area

${ }^{\text {a }} P<0.05$

catheterization was 2.5 days (range 1-120 days). All these patients underwent subsequent surgery after a median interval of 27 days (range 0-197 days).

Surgical repair was performed at a median age of 7 days (range 1-225 days) and a weight of $3.1 \mathrm{~kg}$ (range 1-5.5 days). Two children required more than one operation during initial treatment. Cardiopulmonary bypass was required for 16 patients $(41 \%)$. The surgical techniques used are listed in Table 3. Aortic arch reconstruction was needed for either aortic coarctation or interrupted aortic arch in 32 children (82\%). Additional atrial septal defect closure was performed in five cases $(13 \%)$, once with fenestration.

The median intensive care unit (ICU) time was 9 days (range 3-51 days). The intubation time was 5 days (range 1-51 days), and the hospital stay was 32 days (range 3-100 days). 
Table 3 Surgical repair

\begin{tabular}{lc}
\hline Surgery & $n=39$ \\
\hline Coarctation repair & 25 \\
With additional mitral valve reconstruction & 2 \\
Interrupted aortic arch repair and VSD closure & 8 \\
With VSD fenestration & 1 \\
With additional relief of subaortic stenosis & 2 \\
Aortic valve reconstruction & 5 \\
With additional mitral valve reconstruction & 3 \\
Ross-Konno procedure & 1 \\
\hline
\end{tabular}

VSD ventricular septal defect

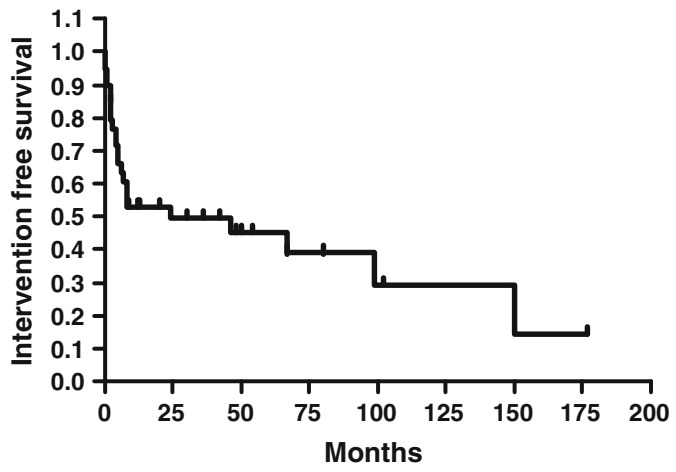

Fig. 1 Kaplan-Meier estimate of freedom from reinterventions $(n=39)$

Postoperative complications occurred for 12 patients (31\%), including: arrhythmias in 4 (2 tachycardias requiring medical treatment and 2 postoperative transient thirddegree atrioventricular blocks), pericardial effusion or hematopericard in 3, diaphragmatic paralysis, chylotorax or paralysis of the recurrent laryngeal nerve in 2 and sternal infection in 1 cases each. Three children experienced more than one complication. Postoperative nitric oxide ventilation was necessary for four children with pulmonary hypertension.

\section{Reinterventions}

During a median follow-up period of 34 months (range 1-177 months), the overall reintervention rate was $62 \%$. The 1-year intervention-free survival rate was $50 \%$ (Fig. 1).

A total of 39 reinterventions, performed for 23 of the initial 37 survivors, consisted of 31 redo surgeries and 18 cardiac catheterizations. Redo surgery was necessary for 21 of the 37 patients (57\%), with 13 children undergoing one reoperation, 6 children undergoing two reoperations, and 2 children requiring three reoperations. Six $(75 \%)$ of the eight patients with repaired interrupted aortic arch had redo surgery (4 for isolated recurrent LVOT or AO obstruction,
Table 4 Reinterventions

\begin{tabular}{|c|c|c|c|}
\hline Surgical reinterventions $(n=31)$ & $\begin{array}{l}\text { First } \\
(n=21)\end{array}$ & $\begin{array}{l}\text { Second } \\
(n=8)\end{array}$ & $\begin{array}{l}\text { Third } \\
(n=2)\end{array}$ \\
\hline Ross-Konno procedure & 3 & & \\
\hline Aortic arch repair & 5 & 1 & \\
\hline With additional VSD closure & 1 & & \\
\hline With additional LVOTO relief & 1 & & \\
\hline $\begin{array}{l}\text { With additional LVOTO relief and } \\
\text { VSD closure }\end{array}$ & 1 & & \\
\hline AO reconstruction & 1 & 2 & \\
\hline With additional MV reconstruction & & 1 & \\
\hline LVOTO relief & 4 & 4 & 1 \\
\hline With additional MV reconstruction & 1 & 1 & 1 \\
\hline With additional RVOTO relief & 1 & & \\
\hline With additional ASD closure & 1 & & \\
\hline MV reconstruction & 3 & & \\
\hline $\begin{array}{l}\text { With additional ASD and/or VSD } \\
\text { closure }\end{array}$ & 2 & & \\
\hline $\begin{array}{l}\text { MV replacement (Carbomedics) } \\
\quad(16 \mathrm{~mm})\end{array}$ & & 1 & \\
\hline ASD and/or VSD closure & 5 & & 1 \\
\hline With ASD fenestration & 2 & & \\
\hline $\begin{array}{l}\text { Catheter-guided reinterventions } \\
\quad(n=8)\end{array}$ & $\mathrm{n}=6$ & $\mathrm{n}=2$ & \\
\hline Aortic arch angioplasty & 3 & 1 & \\
\hline AO valvuloplasty & 2 & & \\
\hline MV valvuloplasty & & 1 & \\
\hline Pulmonary artery dilation & 1 & & \\
\hline
\end{tabular}

$V S D$ ventricular septal defect; $L V O T O$ left ventricular outflow tract obstruction; $A O$ aortic valve; $M V$ mitral valve; $R V O T O$ right ventricular outflow tract obstruction; $A S D$ atrial septal defect

1 for both recurrent LVOT obstruction and re-coarctation, and 1 for both re-coarctation and VSD closure).

Cardiac catheterization, performed for 18 patients (46\%), consisted of diagnostic catheterization in 10 cases and catheter-guided reintervention in 8 cases. The surgical and catheter-guided reintervention procedures are listed in Table 4.

The initial echocardiographic parameters of the patients who underwent reinterventions during the follow-up period did not differ significantly from those of the patients who did not require any interventions.

\section{Mortality}

The overall mortality rate was $13 \%(n=5)$. One patient died intraoperatively during a Ross-Konno procedure at the age of 6 months after having undergone first balloon valvuloplasty and then surgical reconstruction of the AO for critical aortic stenosis as a newborn. Three patients died perioperatively. The first of the three experienced acute right heart failure after coarctation repair and pulmonary 
artery banding. Extracorporeal membrane oxygenation (ECMO) installation failed because cannulation of the small ascending aorta proved to be impossible. The second patient, with interrupted aortic arch, a large VSD, AO and mitral valve stenosis, and an LV with fibroelastosis, had undergone arch reconstruction and fenestrated VSD closure as a newborn, then aortic commissurotomy at the age of 3 months, and finally $\mathrm{AO}$ reconstruction at the age of 4 months. He died on ECMO on postoperative day 3 after valve reconstruction. The third patient, a newborn with aortic coarctation, hypoplastic aortic arch, and AO stenosis, died on postoperative day 3 after aortic arch reconstruction due to untreatable arrhythmias and low cardiac output.

One patient died at the age of 21 months due to right ventricular failure in persistent pulmonary hypertension. This girl, born with AO stenosis, LV fibroelastosis, and mitral valve insufficiency, had undergone aortic valvuloplasty as a neonate and Ross-Konno procedure at the age of 1 month. Pulmonary hypertension persisted in spite of good surgical results.

\section{Follow-up Evaluation}

At the end of the follow-up period, echocardiography showed adequate growth of the LV structures (Table 2). The $z$-score of the aortic annulus normalized in 29 patients $(85 \%), 5$ of whom still had values of -2 to -3.2 . The LV function was reported as good in all the children. New or residual lesions affecting primarily the $\mathrm{AO}$, mitral valve, or both were observed and included mild to moderate AO stenosis (mean maximum instantaneous Doppler gradient $37 \mathrm{mmHg}$ ) in 10 patients $(29 \%)$, mild to moderate AO regurgitation in 13 patients $(38 \%)$, mild to moderate mitral valve stenosis in 9 patients $(26 \%)$, and mild to moderate mitral valve regurgitation in 7 patients $(21 \%)$.

Furthermore, re-coarctation occurred in four patients (12\%) and subaortic stenosis in five patients (15\%). All the patients with mitral valve regurgitation except one had undergone mitral valve surgery. Four of the nine patients with mitral valve stenosis had undergone previous intervention at the valve. Pulmonary hypertension was documented by echocardiography in five patients $(15 \%)$.

Patient examination and parental reporting determined late functional status at the most recent follow-up clinical visit, with 25 patients $(74 \%)$ categorized as class 1 and 9 patients $(26 \%)$ classified as functional class 2 . A total of 10 patients were receiving cardiac medication (29\%) consisting of angiotensin-converting enzyme (ACE) inhibitors for 6 patients $(18 \%)$ and beta-blockers or diuretics for 5 patients $(15 \%)$. Six patients $(18 \%)$ were receiving more than one medication. Failure to thrive, defined as weight $\leq$ P3 according to the national growth percentiles [16], was observed for 12 surviving children $(35 \%)$ at a median age of 28 months (range 1 month-12 years). Compared with the other patients, the group with failure to thrive did not show any relevant difference in the initial size of the LV or the aortic annulus, growth of these structures after surgical repair, or functional class at the end of the follow-up period. Premature children or children with genetic anomalies were not overrepresented among the patients with failure to thrive.

\section{Discussion}

In this study, we assessed the outcome of neonates with LHL for whom biventricular repair had been determined as the therapy of choice. Although our results show that biventricular repair can be performed safely for patients selected appropriately, this patient group still presents with significant perioperative mortality and postoperative morbidity.

The decision process to determine uni- or biventricular repair for LHL still is an unsolved debate and remains a challenge for pediatric cardiologists. The existing literature often is focused on one single LHL such as aortic coarctation $[1,9,15,23,24]$ or critical aortic stenosis $[6,7,11$, 17, 23]. Reports analyzing LHL often are limited by a small number of patients [3, 4, 13, 20, 22, 25, 26]. Moreover, the various lesions may present in different degrees of severity and manifold combinations.

Assessment of LV size in LHL can be challenging during the newborn period. In the presence of a left-sided obstruction and an atrial septal defect, the LV might be underfilled because of left-to-right shunting at the atrial level and right-to-left shunting at the ductal level [15]. The LV cavity may be compressed and displaced by the dilated and hypertrophied RV and thus may appear small and smashed [1, 9]. After relief of the left-sided obstruction, resulting in decreased pulmonary pressure and normalized LV preload and afterload, the LV may be able to gain its real size. Krauser et al. [9] reported a significant increase in LV volume within 1 week after coarctation repair and normalization of the loading conditions. Minich et al. [13] suggested that persistent fetal circulation may maintain the RV overloaded and the LV unloaded and proposed waiting for hemodynamic adaptation to the extrauterine circulation, if necessary, by maintaining ductal patency with the use of prostaglandin before making any therapeutic decision. In their series of neonates with non-apex-forming LV, regular echocardiographic examinations showed a significant spontaneous growth of the left heart structures after 1 month, and biventricular repair was eventually performed with success in more than $70 \%$ of the cases.

The left-sided cardiac structures tend toward growth and normalization after obstruction relief has been performed 
$[1,6,20]$. In our patients, the size of the aortic annulus normalized, and LV dimensions significantly improved in up to $85 \%$ of the cases. Similar findings are reported in the literature for patients with critical aortic stenosis after neonatal balloon valvuloplasty of the AO [12] and for patients with LHL after coarctation repair, relief of potential LVOT obstruction, or both [1, 20].

Residual narrowing of the LV inflow or outflow may represent a limiting factor for the growth potential of the left heart structures. Because a conservative approach for inflow and outflow obstructions usually is preferred at the time of surgical repair in infancy to minimize the perioperative risks [26], obstructions of the LVOT, the mitral valve, or both are frequently observed during follow-up assessment. A mitral valve anomaly may not even be evident initially. The limited blood volume passing through the valve may let the real pressure gradient be underestimated.

In our study, $30 \%$ of the patients required redo surgery for LVOT obstruction. Three patients underwent RossKonno procedures, and $17 \%$ had redo surgery for mitral valve obstruction. St. Louis et al. [22] studied 28 patients with Shone's complex, who in $89 \%$ of the cases presented initially with aortic coarctation. After coarctation repair, $39 \%$ of the patients required subsequent surgery for mitral valve obstruction and $14 \%$ for LVOT obstruction.

Another group reported a series of 20 patients with LHL and aortic coarctation who experienced LVOT obstruction during follow-up evaluation in $35 \%$ and $\mathrm{LV}$ inflow obstruction in $29 \%$ of the cases, both requiring reoperation [20]. Particularly LVOT obstruction must be considered a major late problem because both the outflow tract and the aortic annulus may not grow proportionally to body size, and a substantial number of reoperations may be required $[25,26]$. In our study, $55 \%$ of the reoperations were performed to relieve recurrent LVOT obstruction at either the subaortic or valve level, and mortality was related mainly to surgery of the LVOT.

A small aortic annulus, hypoplasia or stenosis of the mitral valve, and endocardial fibroelastosis are reported to be risk factors for mortality $[4,7,11,12,14,19,20]$. In our series, the aortic annulus of all nonsurvivors had a $z$-score ranging from -2.8 to -12 at the initial presentation compared with 1.1 to -8.5 for the survivors. Endocardial fibroelastosis was present in three of five deceived patients and in two survivors, who were symptomatic in functional class 2 and receiving cardiac medication. Two of the five deceived patients had a stenotic, parachute mitral valve, but none required mitral valve surgery before death.

The observed high rate of reinterventions with a reintervention-free survival of only $50 \%$ after 1 year is similar to that reported in the literature. Tchervenkov et al. [26] in their series of 11 neonates with LHL undergoing biventricular repair reported a freedom-from-reoperation rate of $25 \%$ at 3 years. In another series of patients with LHL the reoperation rate at 5 years was $62 \%$ [20].

Statistical analysis of different patient subgroups (functional class, failure to thrive, need for reinterventions) did not demonstrate a significant difference in the initial echocardiographic parameters. Thus, our data cannot answer the question of when a good single-ventricle repair may be better than a bad two-ventricle repair. However, our observations show a trend similar to the reports found in the literature suggesting that patients presenting with severe hypoplasia of the aortic annulus $(z$-score $\leq-3)$ or endocardial fibroelastosis may be at a higher risk for failing biventricular repair, even if the size of the remaining leftsided cardiac structures is initially estimated to be sufficient for biventricular repair.

\section{Study Limitations}

The retrospectively collected data did not allow us to provide selection criteria to determine bi- or univentricular repair for patients with LHL. In the assessed patients group, the decision to perform biventricular repair was made on the basis of the echocardiographic findings as well as the personal experience of the pediatric cardiologists and cardiac surgeons involved. Therefore, some patients who had undergone a single-ventricle palliation may have survived a biventricular approach, and other patients who had received a biventricular repair may have had a better prognosis after univentricular palliation.

During the study period, 23 patients with hypoplastic left heart syndrome (HLHS) underwent univentricular repair at our hospital. We chose not to compare the two groups because we believe that children with HLHS have an intrinsically worse prognosis than patients with LHL, in whom forward flow in the ascending aorta is maintained.

The statistical analysis was weakened by the limited number of patients studied. Therefore, we were not able to demonstrate any clear risk factors for poor outcome. Moreover, data collection covered a fairly long period, in which the treatment algorithm and surgical techniques may have evolved.

\section{Conclusions}

Biventricular repair for selected patients with multiple LHL can be performed with a good survival rate $(87 \%)$. Adequate growth of the left-sided cardiac structures can be demonstrated by echocardiography in most patients. Nevertheless, residual or newly developing obstructive LHLs 
are frequent and cause significant morbidity requiring surgical or catheter-guided reinterventions.

\section{References}

1. Alboliras ET, Mavroudis C, Pahl E, Gidding SS, Backer CL, Rocchini AP (1999) Left ventricular growth in selected hypoplastic left ventricles: outcome after repair of coarctation of aorta. Ann Thorac Surg 68:549-555

2. Allen HD, Gutgesell HP, Clark EB, Driscoll DJ (2001) Congenital cardiovascular defects: aortic arch anomalies and left ventricular outflow abnormalities. In: Allen HD, Gutgesell HP, Clark EB, Driscoll DJ (eds) Moss and Adams' heart disease in infants, children, and adolescents 2001. 6th ed. Lippincott Williams \& Wilkins, Philadelphia, pp 707-735 and 970-1026

3. Blaufox AD, Lai WW, Lopez L, Nguyen K, Griepp RB, Parness IA (1998) Survival in neonatal biventricular repair of left-sided cardiac obstructive lesions associated with hypoplastic left ventricle. Am J Cardiol 82:1138-1140 A10

4. Brauner RA, Laks H, Drinkwater DC Jr, Scholl F, McCaffery S (1997) Multiple left heart obstructions (Shone's anomaly) with mitral valve involvement: long-term surgical outcome. Ann Thorac Surg 64:721-729

5. Daubeney PE, Blackstone EH, Weintraub RG, Slavik Z, Scanlon J, Webber SA (1999) Relationship of the dimension of cardiac structures to body size: an echocardiographic study in normal infants and children. Cardiol Young 9:402-410

6. Han RK, Gurofsky RC, Lee KJ, Dipchand AI, Williams WG, Smallhorn JF, McCrindle BW (2007) Outcome and growth potential of left heart structures after neonatal intervention for aortic valve stenosis. J Am Coll Cardiol 50:2406-2414

7. Hickey EJ, Caldarone CA, Blackstone EH, Lofland GK, Yeh T Jr, Pizarro C, Tchervenkov CI, Pigula F, Overman DM, Jacobs ML, McCrindle BW (2007) Critical left ventricular outflow tract obstruction: the disproportionate impact of biventricular repair in borderline cases. Congenital Heart Surgeons' Society. J Thorac Cardiovasc Surg 134:1429-1436

8. Kampmann C, Wiethoff CM, Wenzel A, Stolz G, Betancor M, Wippermann CF, Huth RG, Habermehl P, Knuf M, Emschermann T, Stopfkuchen H (2000) Normal values of M-mode echocardiographic measurements of more than 2,000 healthy infants and children in central Europe. Heart 83:667-672

9. Krauser DG, Rutkowski M, Phoon CK (2000) Left ventricular volume after correction of isolated aortic coarctation in neonates. Am J Cardiol 85:904-907

10. Lai WW, Geva T, Shirali GS, Frommelt PC, Humes RA, Brook MM, Pignatelli RH, Rychik J (2006) Guidelines and standards for performance of a pediatric echocardiogram: a report from the Task Force of the Pediatric Council of the American Society of Echocardiography. J Am Soc Echocardiogr 19:1413-1430

11. Lofland GK, McCrindle BW, Williams WG, Blackstone EH, Tchervenkov CI, Sittiwangkul R, Jonas RA (2001) Critical aortic stenosis in the neonate: a multi-institutional study of management, outcomes, and risk factors. Congenital Heart Surgeons Society. J Thorac Cardiovasc Surg 121:10-27

12. McElhinney DB, Lock JE, Keane JF, Moran AM, Colan SD (2005) Left heart growth, function, and reintervention after balloon aortic valvuloplasty for neonatal aortic stenosis. Circulation 111:451-458

13. Minich LL, Tani LY, Hawkins JA, Shaddy RE (1997) Possibility of postnatal left ventricular growth in selected infants with nonapex-forming left ventricles. Am Heart J 133:570-574

14. Morell VO, Quintessenza JA, Jacobs JP (2004) Biventricular repair in the management of hypoplastic left heart syndrome. Cardiol Young 14(Suppl 1):101-104

15. Page DA, Levine MM (1995) Left ventricular growth in a patient with critical coarctation of the aorta and hypoplastic left ventricle. Pediatr Cardiol 16:176-178

16. Prader A, Largo RH, Molinari L, Issler C (1989) Physical growth of Swiss children from birth to 20 years of age: first Zurich longitudinal study of growth and development. Helv Paediatr Acta Suppl 52:1-125

17. Rhodes LA, Colan SD, Perry SB, Jonas RA, Sanders SP (1991) Predictors of survival in neonates with critical aortic stenosis. Circulation 84:2325-2335

18. Ross RD, Daniels SR, Schwartz DC, Hannon DW, Shukla R, Kaplan S (1987) Plasma norepinephrine levels in infants and children with congestive heart failure. Am J Cardiol 59:911-914

19. Schwartz ML, Gauvreau K, Geva T (2001) Predictors of outcome of biventricular repair in infants with multiple left heart obstructive lesions. Circulation 104:682-687

20. Serraf A, Piot JD, Bonnet N, Lacour-Gayet F, Touchot A, Bruniaux $\mathrm{J}$ et al (1999) Biventricular repair approach in ductodependent neonates with hypoplastic but morphologically normal left ventricle. J Am Coll Cardiol 33:827-834

21. Snider AR, Serwer GA, Ritter SB (1997) The normal echocardiographic examination and methods for obtaining quantitative information from the echocardiographic examination. In: Snider AR, Serwer GA, Ritter SB (eds) Echocardiography in pediatric heart disease 1997. 2nd ed. Mosby-Year Book, St. Louis, pp 22-75, 133-234

22. St. Louis JD, Bannan MM, Lutin WA, Wiles HB (2007) Surgical strategies and outcomes in patients with Shone complex: a retrospective review. Ann Thorac Surg 84:1357-1362

23. Tani LY, Minich LL, Pagotto LT, Shaddy RE, McGough EC, Hawkins JA (1999) Left heart hypoplasia and neonatal aortic arch obstruction: is the Rhodes left ventricular adequacy score applicable? J Thorac Cardiovasc Surg 118:81-86

24. Tani LY, Minich LL, Hawkins JA, McGough EC, Pagotto LT, Orsmond GS (2000) Spectrum and influence of hypoplasia of the left heart in neonatal aortic coarctation. Cardiol Young 10:90-97

25. Tchervenkov CI (2004) Indications, criterions, and principles for biventricular repair. Cardiol Young 14(Suppl 1):97-100

26. Tchervenkov CI, Tahta SA, Jutras LC, Béland MJ (1998) Biventricular repair in neonates with hypoplastic left heart complex. Ann Thorac Surg 66:1350-1357 